\title{
Aerodynamics Analysis of Grid Fins Inner Lattice Structure in Cruise Missile
}

\author{
SHARUL SHAM DOL \\ Department of Mechanical Engineering \\ Abu Dhabi University \\ Abu Dhabi, P.O. Box 59911 \\ UNITED ARAB EMIRATES
}

\begin{abstract}
Grid fins are normally placed at the rear end of cruise missiles, rockets and other ballistic devices to control their trajectory especially at the final stage of flight. These fins provided fine control of the pitch, yaw and other lateral movements, allowing for higher stability and accuracy of the cruise missiles. This project investigates computationally the relation between grid fins inner lattice structures dimensionless parameters and the fins aerodynamics drag coefficient. The project gathered data from 12 different fins by varying the parameters
\end{abstract}

of its internal lattice structure such as thickness, width and chord at various angles of attack $\left(0^{\circ}, 20^{\circ}\right.$ and $\left.40^{\circ}\right)$. The freestream was set at a constant speed of $150 \mathrm{~m} / \mathrm{s}$ that gives Reynolds number $>1.7 \times 10$. The results were experimentally compared by using a re-scaled model of a single fin in a sub-sonic wind tunnel, achieving a difference in results of not exceeding $6 \%$. The results obtained that as the width-chord ratio increases, the aerodynamics drag coefficient increases for fixed thickness-width ratio. The results also demonstrated that as the angle of attack increases, the aerodynamics drag increases. The thickness-width ratio has the larger impact on the aerodynamics drag. The results can be used to improve the design of guided cruise missiles.

Key-Words: - Aerodynamics; Cruise missile; Drag; Grid fins; Lattice structure; Lift; Stability

Received: January 28, 2021. Revised: April 30, 2021. Accepted: May 5, 2021. Published: May 19, 2021.

\section{Nomenclature}

$\begin{array}{ll}c & \text { Chord (fin) } \\ w & \text { Width (fin) } \\ C_{d} & \text { Drag coefficient } \\ C_{x f} & \text { Coefficient of axial friction } \\ C_{l} & \text { Lift coefficient } \\ t & \text { Thickness (fin) } \\ s & \text { Span (fin) } \\ l & \text { Grid fin base } \\ k & \text { Turbulent kinetic energy }\end{array}$

\section{Introduction}

A missile is like an unmanned aerial system, with payloads and without the facility of an undercarriage for landing. In addition, a missile is a launch and forget projectile, fired without any intention of retrieval. While a missile is subject to the same forces of lift, drag, thrust, and other forces, the wings or fins are only provided for stability, to prevent rotation and wobble, and they have limited role in providing the lift [1-3]. Speed control is not available on missiles, and it will fly at the designed speed until it hits the target.
AOA Angle of Attack
Re Reynolds number
$M a \quad$ Mach number
$U \quad$ Fluid velocity
$\rho \quad$ Fluid density
$\mu \quad$ Dynamic viscosity
CP Coefficient of pressure
CG Centre of gravity
SST Shear stress transport 
higher control of the missiles. To reduce the weight, grid fins usually have an outer frame with an internal lattice structure made of thin walls. A small chord is used rather than installing a single structure airfoil. Grid fins are arranged at a normal to the airflows. They have a spring hinge mechanism that allows them to be restrained and folded flat with the missile body in order to be placed/installed within canisters. This feature prevents damage during mounting and launch in the missile pods. After launch, a signal allows the grid fins to be released to their required position.

Grid fins are efficient at supersonic flows, and they do not perform well in transonic flows, since in such flows, shockwaves are generated at the front of the fins. These shock waves act as a barrier to the free stream airflow through the lattice, generating a higher drag. Another benefit is that grid fins have a high stall angle, and studies have shown that missiles with grid fins do not stall at 30-degree attack angle [4]. Therefore, grid fins help to provide efficient control over the projectile, they provide stability, and they can act as speed brakes [5]. The disadvantage is that they create cross flows, and increase the radar cross section (visibility) of the missile making it an easy target to be detected by radars [6]. Figure 1 shows an image of a missile with a grid fins (folded and unfolded).

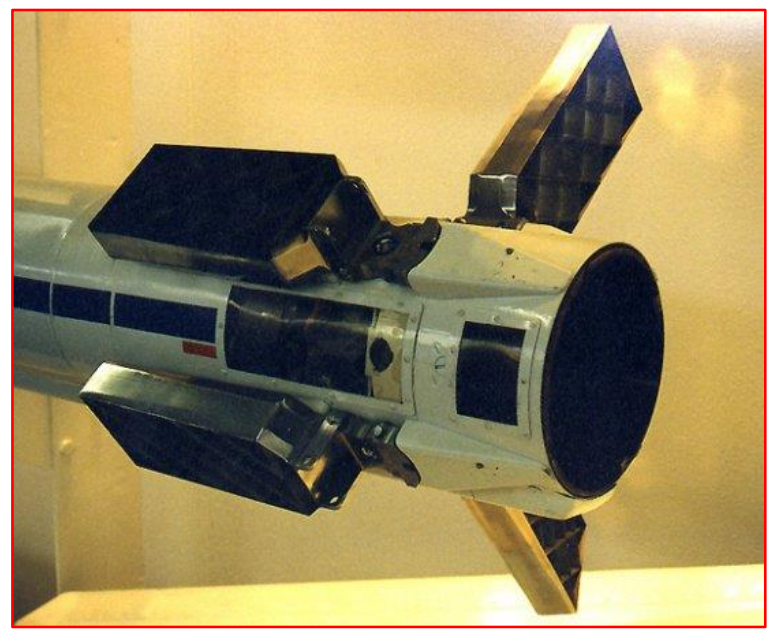

Figure 1: Folded grid fins used on the R-77 (AA12) missile [6]

Grid fins are used on a large number of missile systems such as Massive Ordnance Air Blast (MOAB), SS-12 Scaleboard, SS-25 Sickle, SS-20 Saber, SS-23 Spider, SS-21 Scarab, on Soyuz TM-22 capsule, N1 lunar rocket, the AA-12 Adder missile, and on several other guided projectiles as shown in Figure 2. With this background, this paper will include the aerodynamics of grid fins in missiles and concentrating on specific parameters that would affect aerodynamics performance of grid fins [7].
Decrocq et al. [7] are of the opinion that missile aerodynamics are constrained by the launching systems, motion of the launch vehicle, strong winds and waves, the external shape, and these factors increase the drag, weight, and impact the stability and maneuverability. There have been many instances of missiles crashing due to several factors, one of them being poor aerodynamic study and analysis. Several factors are considered to retain the aerodynamics of a missile. These include propulsion, guidance, warhead and fuzzing, autopilot and control, sensor dome bluntness, etc. Air inlets for subspace missiles, or missiles that travel within the atmosphere are placed in areas that do not degrade the aerodynamic inferences actions such as wakes, vortices, and shockwaves [8-9]. Air inlets degrade the performance and increase the drag, and therefore, these are located to improve lift, thrust, and stability. When fuel is burnt, the center of gravity shifts, changing the controllability and this problem is more in solid-fuels than in liquid-fuel missiles. If strap on booster systems are used, these are jettisoned after providing the initial boost, and they offset the center of gravity.

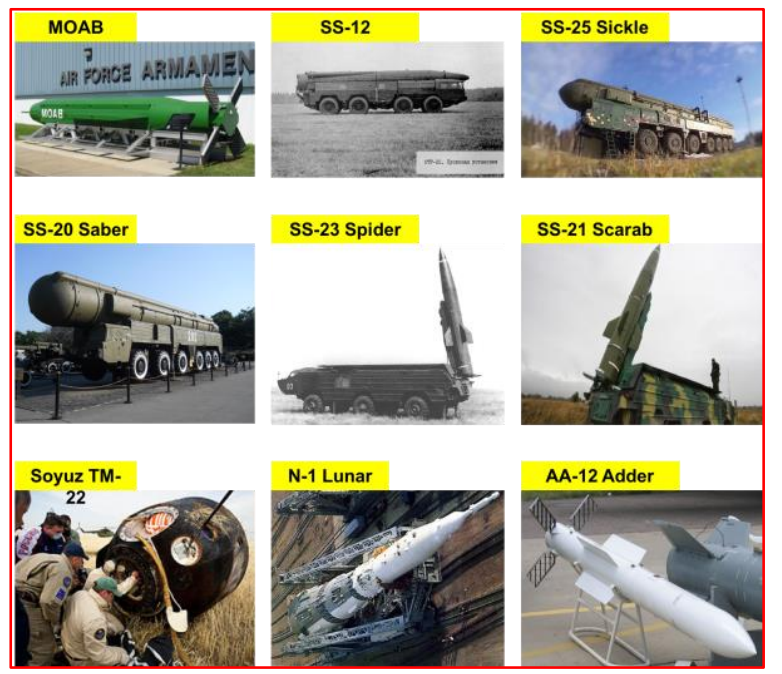

Figure 2: Projectiles with grid fins

Decrocq et al. [7] also point out that aerodynamic design of missiles faces some problems, and these include geometric limitations, CG travel, CP variation with Mach number, high attack angle, launching environment, multi staging and dynamic separation, pressure distribution, panel loads and momentum, elasticity, and others. Among these, multi-stage booster separation is critical, especially in Intercontinental ballistic missiles. The separation must be clean, instantaneous, and the axial forces on the booster must be much higher than the axial forces acting on the missile. Short range missiles such as airto-air sidewinder missiles travel for a short range, and they may not face some of the problems, listed above. 
Faza et al. [10] studied the aerodynamic characteristics of grids fins without sweptback angle and compared to another grid fin with a different sweptback angle. Computational fluid dynamics method with simulation was used as a tool to study their performance of the fins. Standard sizes of fins were considered with reference to the spacing $s$. Width of the fins was $160 \mathrm{~mm}$ and height was $240 \mathrm{~mm}$ with lattice size of $80 \mathrm{~mm}$ at 45 degrees wall, and frame thickness was $2 \mathrm{~mm}$. The same fins were used with a 30 degrees' sweptback configuration. CFD allowed simulation of fluid flow inside the lattices grids and around the fins. ANSYS was used to solve the CFD simulations, and this is based on the Reynolds Averaged Navier-Stokes (RANS) method, which has high accuracy but requires larger memory and computing power. $k-\varepsilon$ turbulence model helped to solve the turbulence flows. Boundaries were adjusted to provide for multiple attack angle, and the number of mesh elements was increased to bring the drag coefficient to zero. Tests were run with conditions of 10,000 meters above sea level and at Mach 2. The results show that fins without swept-back angle had the highest drag coefficient at all attack angle. The 30degree swept angle had the least drag coefficient. Testing was done for swept-forward configuration, and these had the highest drag. Tests were run to see the lift vs. attack angle, and the 5-degree swept back had the highest lift while the 30-degree had the lowest lift coefficients.

Huang et al. [11] studied the static aero-elastic effects. Simulations were conducted with a CFD using a structural flexibility method for supersonic and transonic environments. Radial basis function was used to develop a coupling system with fluid-structure interpolation along with volume-mesh moments. CFD-CSD is used to decouple the fluid interaction issues and helped to understand the aerodynamic forces along with structural moments. A geometric model was created with a length of 52 inches, 1 15inch ogive tangent dome, with the diameter of 5 inches. Four fins were placed at a point of 2 calibers in front of the base. Internal web thickness was 0.008 inches and the chord length was 0.384 inches. The 3D model was built with a finite mesh element method, and material of the grid was copper. A spring model was used to simulate the joint stiffness. Aerodynamic loads were computed with CFD. Results were calculated for vertical and horizontally mounted fins. Horizontal fins indicate that as the axial forces increased, deformation sweeps back the fins and move the CP. This reduces and reverses the movement of the hinge. In the case of vertical fins, incidences rise because of deformation and the deformed normal forces is larger than the applied forces. When the attack angle is high, the original and deformed forces are reduced, mainly due to the interference from vortices on the fin [12].

Faza et al. [10] studied swept grid fins and its potential for use in high speed performance missiles. The researchers developed numerical simulations of supersonic environment for conventional swept planar as well as grid type lattice fins. Direct force measurements were carried out at the finite spans in a Ludwieg Tube Facility, a wind tunnel. Studies were carried out in free stream Mach numbers from 2-6 attack angles that ranged from 0-10 degrees. Performance was observed using a zero lift drag and lift-to-drag ratio for the main parameters of the wing. The results show that the new design has a benefit of $30-40 \%$ for the parameters of the zero-lift total drag.

Despeyroux et al. [13] point out that during transonic flight, the grid fins introduce a high drag due to internal flow field characteristics in the lattices. During this regime, flows formed in the cells are choked, leading to deceleration of flow in upstream. This behavior indicates that the grid fins serve as obstacles, increasing the drag force, and acting as brakes. The lift curve slope that shows the effectiveness reduces in transonic flights since shock waves are developed in the cells. Burkhalter et al. [14] have supported this view and they argue that this reduction as the measure of loss in the dynamic pressure, caused by choking. Pitch moment and normal forces show a reduction in control effectiveness, called the transonic bucket. At low supersonic and high supersonic flights, the lattices create an up wash and downwash, reducing the drag coefficient. For Mach numbers below 1, the drag forces are high and some important geometry with sweptback models and sharp leading edge are developed.

Figure 3 illustrates different geometries and types of grid fins. As seen in the figure, the top row shows from left to right, the flat and sweptback fins. The bottom row shows from left to right, flat, valley-type, and peak-type. These are used for missiles, based on the payload, type of launcher, and environmental conditions. An important aspect is that interactions of the fins and body generate localized conditions for the $M a$, yaw and attack angle, and therefore, the local force coefficients need to be matched to each missile type [15]. When normal forces on the missile are compared with the forces of the body, then some differences would be seen, and this difference increases when the attack angle is more than 10 degrees. All the Mach numbers and the critical attack 
angle related to the maximum lift are more than a monoplane missile. When multiple fins are used, they create a higher lift and reduce the drag. The axial coefficient of a grid fin is made of the axial friction $\mathrm{C}_{x f}$ and the lift $\mathrm{C}_{l}$. The relation is given below. This value is important to ensure that the right amount of lift is available to prevent roll and yaw [16].

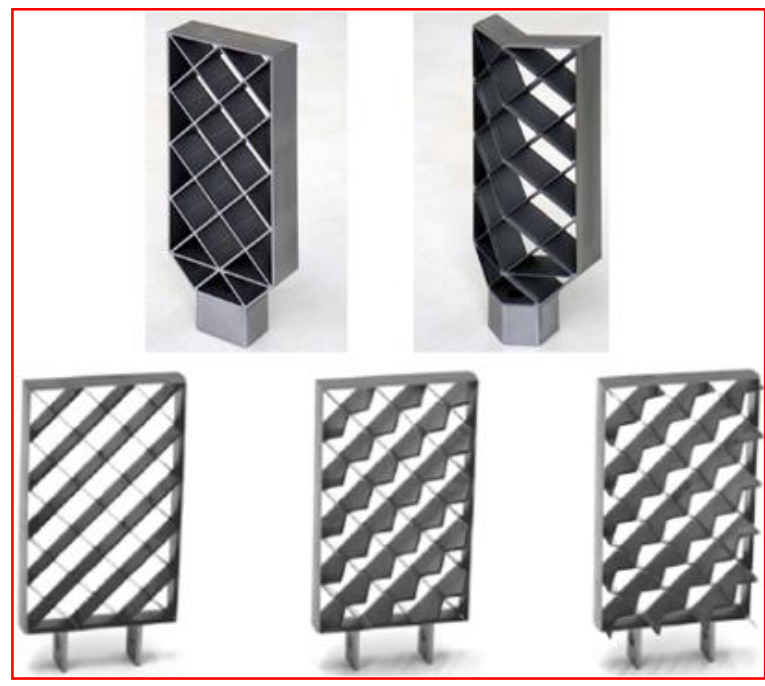

Figure 3: Different geometries of grid fins [16]

Figure 4 illustrates the geometric details of grid fins. Grid fins usually have a flat planform, with blunt trailing and leading edges. The overall size is called span $(s)$, width $(b)$, and chord $(c)$. Width $(w)$ and thickness $(t)$ are details of individual grids or cells, Frame thickness $(t)_{\mathrm{f}}$ is the outer frame dimension used as a structural support for the cells [10].

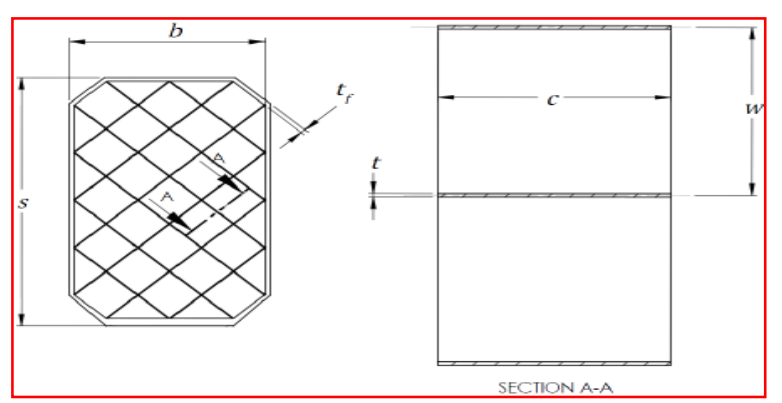

Figure: 4 Geometric details of grid fins [10]

Ledlow [17] clarify that the thickness width ratio $t / w$ and width- chord ratio $w / c$ is important. Leading edge sharpness is $\theta$, and sweptback angle is $\omega$ and these help to reduce the drag in transonic flight. When the leading edge is sharper, the flow is smoother since oblique waves are formed and the bock shock is reduced in transonic flight. The grid cells have a specific geometry and shape, and common shapes are square, triangle, and hexagon. Figure 5 illustrates details of the geometry.

The main objectives of the present work are;
- To investigate the effects of grid fins inner lattice structure parameters on aerodynamics drag.

- To analyse the effects of grid fins' angle of attacks on aerodynamic drags.

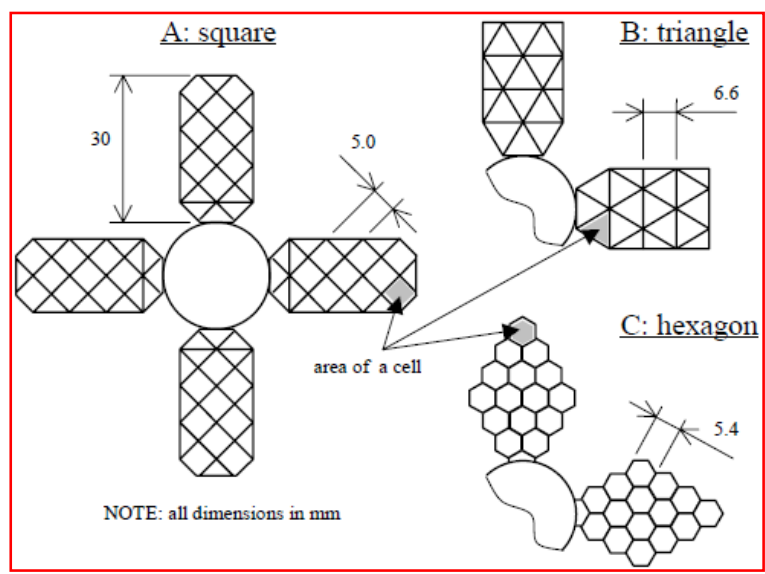

Figure 5: Geometry of cells [17]

\section{Methodology}

\subsection{Geometry}

The missile was designed with a length of $6.4 \mathrm{~m}$ and a diameter of $0.58 \mathrm{~m}$ using the Spaceclaim as shown in Figure 6.

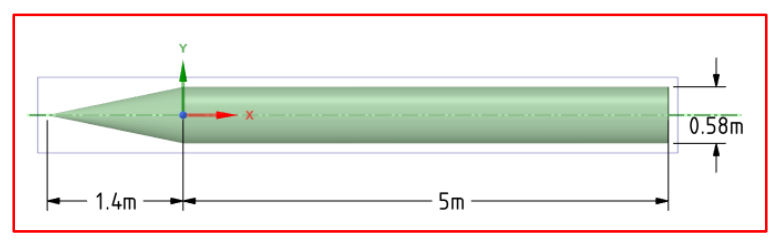

Figure 6: Dimensions of missile used for analysis

\subsection{Meshing}

All cases have similar mesh type (Tetrahedron) with face sizing of $0.0015 \mathrm{~m}$ on all grid fins (four fins) mounted on the missile and a first layer thickness of $0.002 \mathrm{~m}$ as well as the mesh quality is set to high. Number of elements for all cases range from 7 million to 13 million elements dependent on the case (number of elements increased/decreased due to the change in surface area of the missile and the difference in the angle of attack, AOA). Figure 7 and 8 illustrate the mesh for Fin 10 at AOA $0^{\circ}$ and Fin 12 at AOA $40^{\circ}$ (fin geometries will be described in the next subheading).

To validate the model, mesh intensity has been varied by decreasing the size of grid fin face sizing for Fin 5 at angle of attack $0^{\circ}$, which the results are displayed in Table 1. It is noticed that there is a slight difference in the results obtained as the face sizing of the mesh decreases from $0.0025 \mathrm{~m}$ towards $0.002 \mathrm{~m}$ 
$(0.89 \%-1 \%)$, which is considered to be in the acceptable range, therefore face sizing of $0.0015 \mathrm{~m}$ has been used for all cases to achieve accurate results.

Table 1 Mesh Intensity Result for Fin 5 at AOA $0^{\circ}$

\begin{tabular}{|c|c|c|c|c|}
\hline 氮青 & 0.005 & 0.0025 & 0.002 & 0.0015 \\
\hline 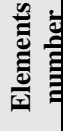 & 957,279 & $3,428,511$ & $5,327,666$ & $9,455,322$ \\
\hline 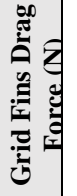 & 550.6 & 586.5 & 591.8 & 598.8 \\
\hline
\end{tabular}

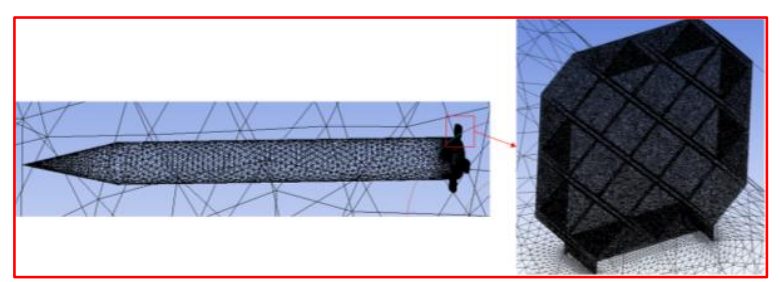

Figure 7: Mesh for Fin 10 at AOA $0^{\circ}$

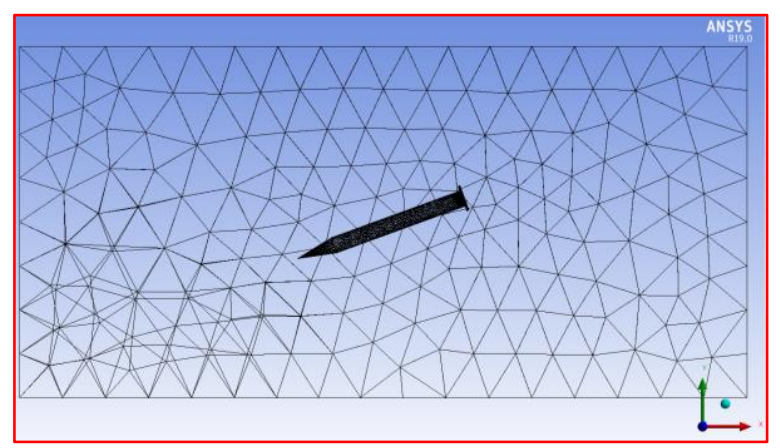

Figure 8: Mesh for Fin 12 at $\mathrm{AOA} 40^{\circ}$

\subsection{Grid Fins Design}

Figure 9 illustrates the grid fin mesh. 12 different grid fins have been created with various lattice structure parameters as shown in Figure 10.

\subsection{CFD Model}

SST $k-\omega$ in ANSYS Fluent, which provides accurate results for flow separation and turbulence simulation especially when analysing high-speed flow conditions was used to model the grid fins flow. The equations are based on the followings;

SST k-omega governing equations [18-20];

Turbulence Kinetic Energy $\frac{\partial k}{\partial t}+U_{j} \frac{\partial k}{\partial x_{j}}=P_{k}-\beta^{*} k \omega+\frac{\partial}{\partial x_{j}}\left[\left(v+\sigma_{k} v_{T}\right) \frac{\partial k}{\partial x_{j}}\right](1)$

Kinematic Eddy Viscosity

$v_{T}=\frac{a_{1} k}{\max \left(a_{1} \omega, S F_{2}\right)}$

Fins with different parameters (regarding width, ratio and chord) each was solved at 3 different angles of attack $\left(0^{\circ}, 20^{\circ}\right.$ and $\left.40^{\circ}\right)$ at a constant speed of $150 \mathrm{~m} / \mathrm{s}$. The Reynolds number was calculated for the free stream flow towards the grid fins using Equation (3). With the $U=150 \mathrm{~m} / \mathrm{s}$ and grid fin base dimension of $0.1717 \mathrm{~m}$, that give $R e$ in the excess of 1.7 million (fully turbulent flow) but still in the subsonic flow region. There are many cruise missiles operating at this range (example see [7]).

$R e=\frac{\rho U l}{\mu}$

Equation (4) defines the two contributing components of the overall coefficient of drag $c_{d}$, friction drag donated by $D_{f}$ and pressure drag $D_{p}$;

$c_{d}=\frac{D_{f}+D_{p}}{q_{\infty} S}$

\subsection{Wind Tunnel Experiment}

For verification of computational results, a single fin (Fin 6) has been rescaled as shown in Figure 11 in order to be printed (using 3D printer type ProJet MJP 3600 Series) and tested in a wind tunnel (Type C1510 Armfield) at Khalifa University in Abu Dhabi. The testing area had a blockage ratio of $4.8 \%$ in comparison to the $5.0 \%-5.3 \%$ which was generally accepted as sufficiently low to avoid significant wall interference effects [21-23].

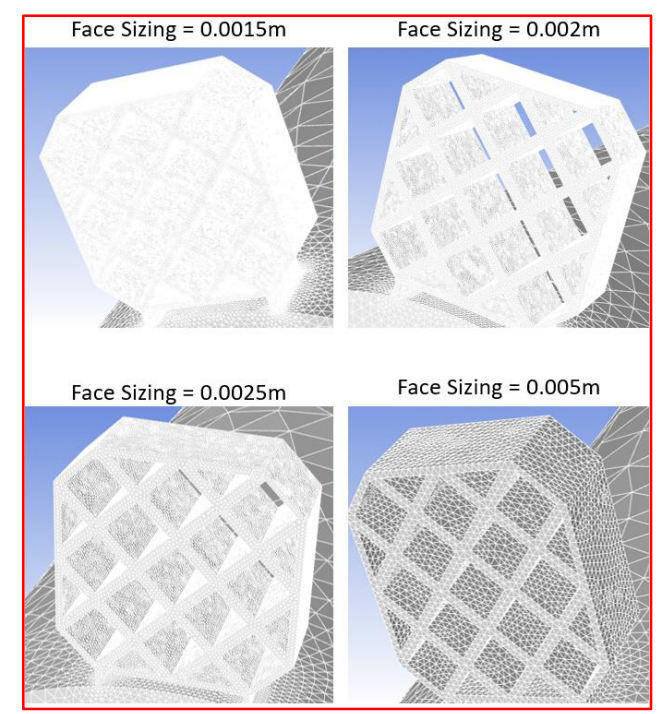

Figure 9: Mesh Intensity on Fin 5 


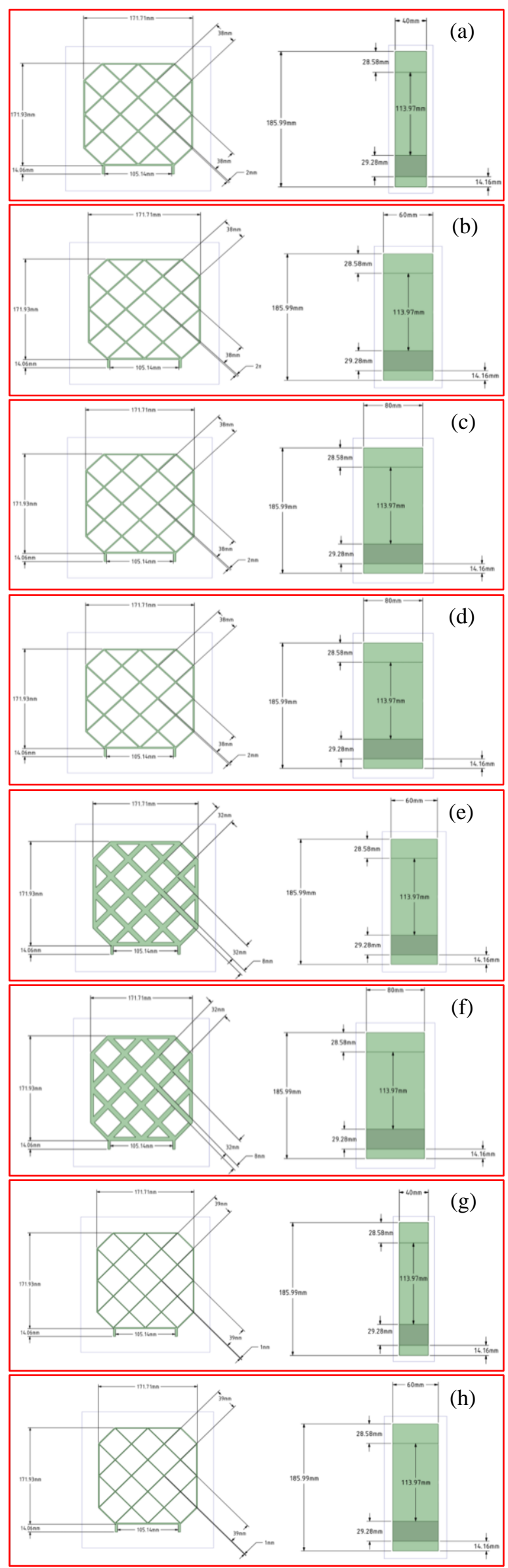

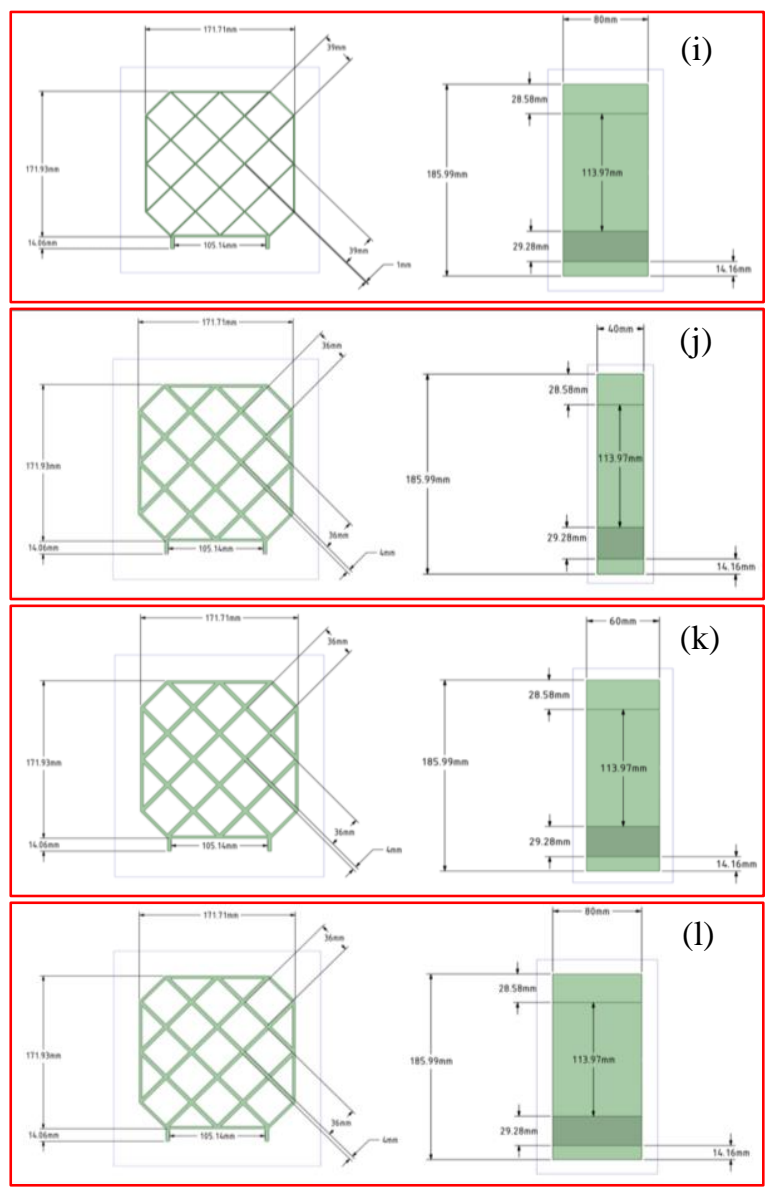

Figure 10: Grid Fins Dimensions (a) Fin 1 (b) Fin 2 (c) Fin 3 (d) Fin 4 (e) Fin 5 (f) Fin 6 (g) Fin 7 (h) Fin 8 (i) Fin 9 (j) Fin 10 (k) Fin 11 (l) Fin 12

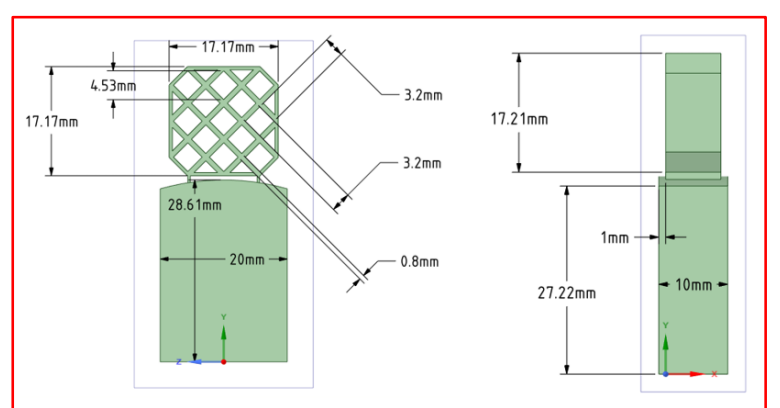

Fig. 11 Fin 6 Rescaled Dimensions and Mount Attachment

\section{Results and Discussion}

Results comparison are illustrated in Figure 12, 13 and 14. It is noted for all fins (at fixed $t / w$ ratio) that as $w / c$ ratio increase there is an increase in the drag coefficient; for Fin 3, Fin 2 and Fin $1 w / c$ is 0.475, 0.633 and 0.950 respectively and the drag coefficient at angle of attack $0^{\circ}$ increased by $25 \%$ from Fin 3 to Fin 2 and by $32 \%$ from Fin 2 to Fin 1. At angle of attack $20^{\circ}$ the drag coefficient increased from Fin 3 to Fin 2 by $19 \%$ and by $20 \%$ from Fin 2 to Fin 1 . 
Results obtained appraised that as $t / w$ ratio increases the initial drag coefficient (at highest value of $w / c$ ratio and different angles of attack) has a higher value. As an example from collected data, for Fin 4 at $t / w=0.25, w / c=0.8$ and angle of attack $0^{\circ}$ the drag coefficient is 0.080358 , when compared to Fin 10 with lower $t / w$ ratio (by 55\% at 0.1111 ) the drag coefficient at the same angle of attack is 0.038761 (lower by $51 \%)$.

In all cases it is notable that for each fin as the angle of attack increases from $0^{\circ}$ to $40^{\circ}$ the drag coefficient increases significantly, for Fin 7 the drag coefficient increased by $76 \%$ from $0^{\circ}$ to $20^{\circ}$ and by $40 \%$ from $20^{\circ}$ to $40^{\circ}$.

It is noted in the results collected for all cases that as the $w / c$ ratio increases the drag coefficient increases yet the highest increase in drag coefficient was noticed to be as the $t / w$ ratio increases but still affected by the angle of attack, where the higher the $t / w$ ratio the higher the initial drag coefficient (at $\mathrm{AOA}=0^{\circ}$ ), as the angle of attack increases there is a slight increase in the highest value of $t / w$ ratio and a high increase in other cases (when $t / w<0.25$ ).

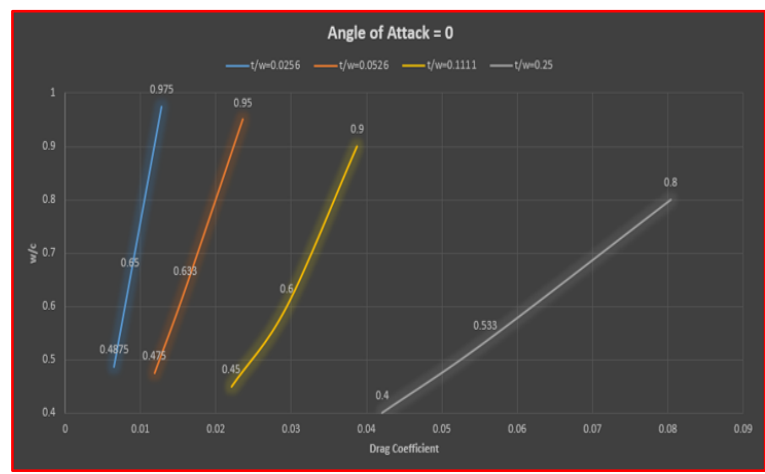

Figure 12: Results Comparison at $\mathrm{AOA} 0^{\circ}$

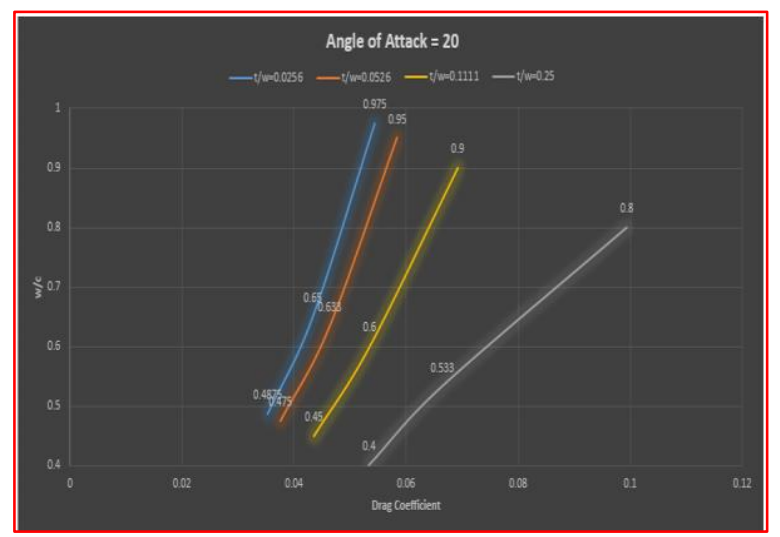

Figure 13: Results Comparison at AOA 20

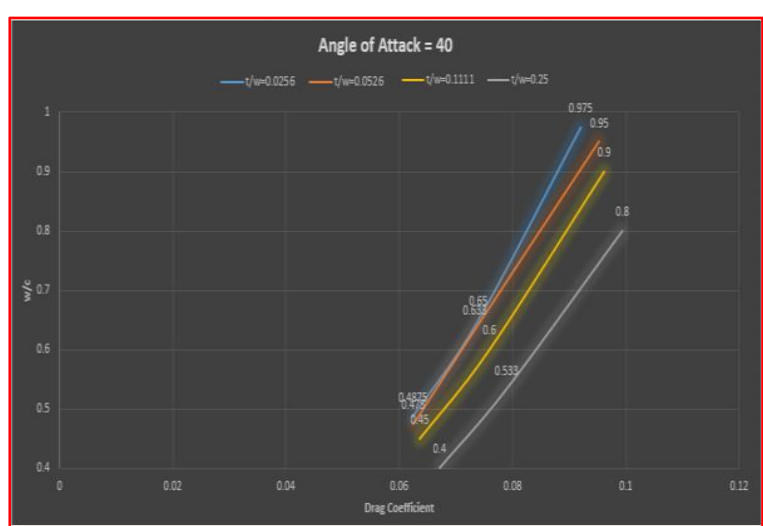

Figure 14: Results Comparison at $\mathrm{AOA} 40^{\circ}$

For Fin 3 at angle of attack $0^{\circ}$ the velocity magnitude reached up to $186 \mathrm{~m} / \mathrm{s}$ at the lattice structure of the grid fin increasing by $20 \%$ and as the angle of attack increased to $20^{\circ}$ and $40^{\circ}$ the velocity increased respectively in the same location to $268 \mathrm{~m} / \mathrm{s}$ and $272 \mathrm{~m} / \mathrm{s}$ (increase by $30-31 \%$ from initial angle of attack), as shown in Figure 15.

When comparing Fin 3 to another Fin with higher $t / w$ ratio such as Fin 6 it is noted that the velocity is higher at angle of attack $0^{\circ}$ as illustrated in Figure 16 increasing by $10 \%$, yet it is lower by $10 \%$ as the angle of attack increases to $20^{\circ}$ then reaching the same value of velocity at $40^{\circ}$ as shown in Figure 16. Comparing Fin 3 to Fin 9 with a lower $t / w$ ratio the velocity at $0^{\circ}$ and $20^{\circ}$ is slightly less (by $4 \%$ ) and similar at $40^{\circ}$ as shown in Figure 17.

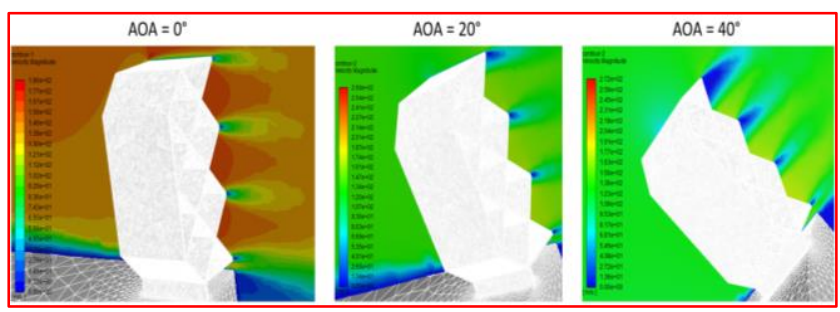

Figure 15: Velocity Comparison at Different AOA (Fin 3)

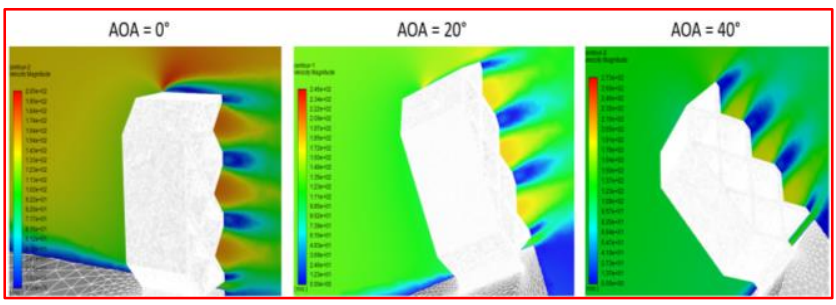

Figure 16: Velocity Comparison at Different AOA (Fin 6) 


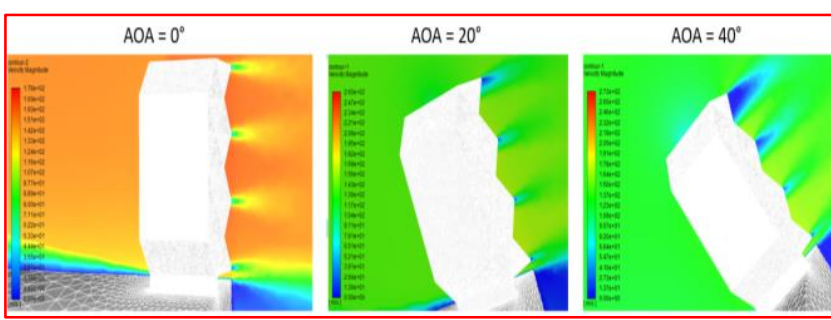

Figure 17: Velocity Comparison at Different AOA (Fin 9)

Similarly, the total pressure increased slightly as the angle of attack increased from $0^{\circ}$ to $40^{\circ}$ in all cases, In Fin 8 for example, the total pressure increased from 15,900 $\mathrm{Pa}$ to $19,200 \mathrm{~Pa}$ from $0^{\circ}$ to $20^{\circ}$ then up to $19,900 \mathrm{~Pa}$ at $40^{\circ}$ as shown in Figure 18. With a higher $t / w$ ratio, Fin 11 (at $t / w=0.1111$ ), the initial total pressure at angle of attack $0^{\circ}$ was 18,800 $\mathrm{Pa}$, higher than Fin 8 by $15 \%$. It increased as the angle of attack increased, $19,100 \mathrm{~Pa}$ at $20^{\circ}$ and $19,300 \mathrm{~Pa}$ at $40^{\circ}$, lower by $0.5 \%$ at $20^{\circ}$ and by $3 \%$ at $40^{\circ}$. Total pressure contours of Fin 11 at different angles of attack are illustrated in Figure 19.

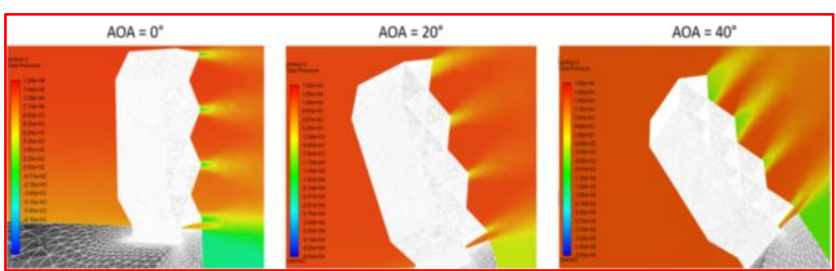

Figure 18: Total Pressure Contours at Different AOA (Fin 8)

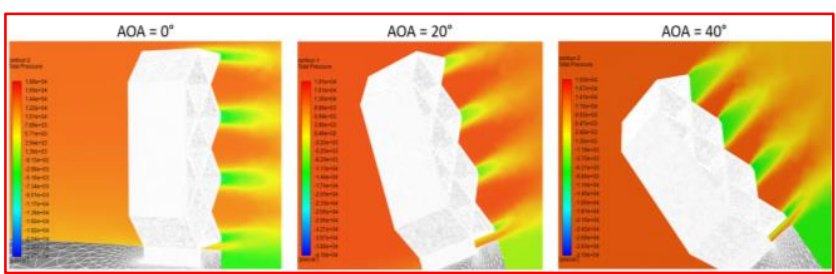

Figure 19: Total Pressure Contours at Different AOA (Fin 11)

Three results have been obtained for Fin 6 using the wind tunnel at different angles of attack as shown in Figure 20 and then compared to results obtained using ANSYS Fluent as shown in Table 2.

Table 2 Wind Tunnel and CFD Result Comparison

\begin{tabular}{|c|c|c|c|c|}
\hline 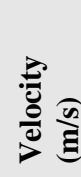 & 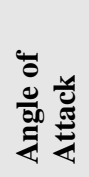 & 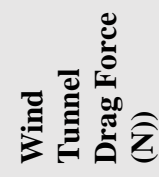 & 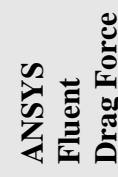 & 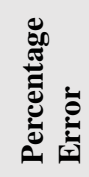 \\
\hline 37.4 & $0^{\circ}$ & 0.74 & 0.70 & $5.4 \%$ \\
\hline 37.1 & $20.2^{\circ}$ & 0.70 & 0.69 & $1.4 \%$ \\
\hline 36.8 & $40^{\circ}$ & 0.68 & 0.67 & $1.4 \%$ \\
\hline
\end{tabular}

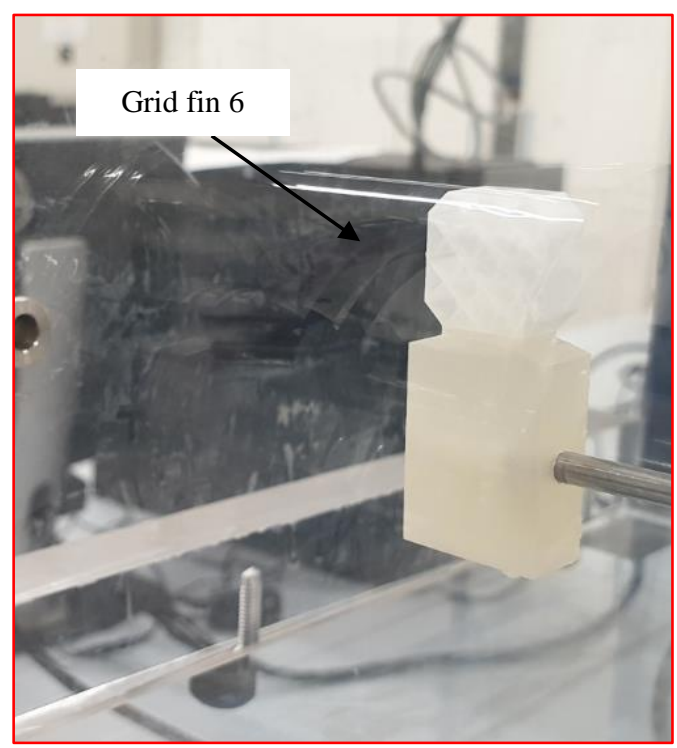

Figure 20: Grid Fin 6 inside Wind Tunnel Enclosure Section

\section{Conclusion}

In conclusion, the paper has gone through introduction of missiles aerodynamics, grid fins as well as important equations and definitions of grid fin structural parameters. ANSYS Fluent computation has been conducted successfully for all fins at different cases (Angles of Attack of $0^{\circ}, 20^{\circ}$ and $40^{\circ}$ ) with constant speed of $150 \mathrm{~m} / \mathrm{s}$. The results obtained prove that there is a relation between the dimensionless parameters of the fins and the fins' drag coefficient; as the $w / c$ ratio decreases the drag coefficient decrease and as the $t / w$ increase the initial drag coefficient is higher (at AOA $=0^{\circ}$ ). Results has been verified experimentally using a wind tunnel and rescaling a single fin.

The data collected serves as a base for further studies and research to be done such as varying the speed at subsonic to supersonic and increasing the number of data to be collected by increasing the number of fins variating the lattice structural parameters and trying at different angles of attack.

\section{Acknowledgment}

The wind tunnel experiment was conducted at Khalifa University in Abu Dhabi UAE.

\section{References}

[1] El-Mahdy, L. A., M. Y. M. Ahmed, O. K. Mahmoud, and O. E. Abdel-Hameed. "EXPERIMENTAL, COMPUTATIONAL, AND EMPIRICAL EVALUATION OF 
SUPERSONIC MISSILE AERODYNAMIC COEFFICIENTS." In The International Conference on Applied Mechanics and Mechanical Engineering, vol. 17, no. 17th International Conference on Applied Mechanics and Mechanical Engineering, pp. 1-15. Military Technical College, 2016.

[2] Azeez, Abid Abdul, Mohamed Gadala, Nasr Al Khudhiri, and Sharul Sham Dol. "Aerodynamics Optimization of RC Plane Winglet." In 2019 8th International Conference on Modeling Simulation and Applied Optimization (ICMSAO), pp. 1-5. IEEE, 2019.

[3] Dol, Sharul Sham. "Aerodynamic optimization of unmanned aerial vehicle for offshore search and rescue (SAR) operation." In IOP Conference Series: Materials Science and Engineering, vol. 715, no. 1, p. 012015. IOP Publishing, 2020.

[4] ElGhazali, A. F., and S. S. Dol. "Aerodynamic Optimization of Unmanned Aerial Vehicle through Propeller Improvements." Journal of Applied Fluid Mechanics 13, no. 3 (2020): 793803.

[5] Lai, Jiang, Zhongliang Zhao, Xiaobing Wang, Hao Li, and Qian Li. "Numerical investigation of pitch motion induced unsteady effects on transverse jet interaction." Aerospace Science and Technology 105 (2020): 106005.

[6] Debiasi, Marco, and Yan Zeng. "Forces and moments generated by swept-back grid fins with sharp leading edges." Journal of Aircraft 53, no. 6 (2016): 1964-1968.

[7] Decrocq, Cédric, Bastien Martinez, Marie Albisser, Simona Dobre, Patrick Gnemmi, Yannick Bailly, and Jean-Claude Roy. "Aerodynamic prediction of a projectile fitted with fins." International Journal of Numerical Methods for Heat \& Fluid Flow (2018).

[8] Khan, Mohammad Osama, Mohammad Anas Khan, and Sharul Sham Dol. "Effects of Chevrons on the Acoustic Noise and Velocity Patterns of Aircraft Nozzles." In 2020 International Conference on Decision Aid Sciences and Application (DASA), pp. 845-849. IEEE, 2020.
[9] Zayed Almheiri, Rawan Aleid, Sharul Sham Dol, "Design of Fixed-Wing and Multi-Copter Hybrid Drone System for Human Body Temperature Measurement during COVID-19 Pandemic", WSEAS TRANSACTIONS ON SYSTEMS, 20, pp. 31-39, 2021.

[10] Faza, G. A., H. Fadillah, F. Y. Silitonga, and Mochamad Agoes Moelyadi. "Study of Swept Angle Effects on Grid Fins Aerodynamics Performance." In Journal of Physics: Conference Series, vol. 1005, no. 1, p. 012013. IOP Publishing, 2018.

[11] Huang, Chengde, L. I. U. Wen, and Y. A. N. G. Guowei. "Numerical studies of static aeroelastic effects on grid fin aerodynamic performances." Chinese journal of aeronautics 30, no. 4 (2017): 1300-1314.

[12] Peng, K., F. Hu, D. Wang, P. N. Okolo, M. Xiang, G. J. Bennett, and W. Zhang (2018). Grid fins shape design of a launch vehicle based on sequential approximation optimization. Advances in Space Research 62(7), 1863-1878.

[13] Despeyroux, Antoine, Jean-Pierre Hickey, Robert Desaulnier, Ryan Luciano, Michael Piotrowski, and Nicolas Hamel. "Numerical analysis of static and dynamic performances of grid fin controlled missiles." Journal of Spacecraft and Rockets 52, no. 4 (2015): 12361252.

[14] Burkhalter, John E., Roy J. Hartfield, and Todd M. Leleux. "Nonlinear aerodynamic analysis of grid fin configurations." Journal of Aircraft 32, no. 3 (1995): 547-554.

[15] Liu, Yuanchun, Zhi-xun Xia, and Jun Liu. "Numerical simulation of aerodynamic characteristics and heating for grid fin missiles." Proceedings of the Institution of Mechanical Engineers, Part G: Journal of Aerospace Engineering 233, no. 7 (2019): 23682377.

[16] Dikbaş, Erdem. "Design of a grid fin aerodynamic control device for transonic flight regime." Master's thesis, MIDDLE EAST TECHNICAL UNIVERSITY, 2015.

[17] Ledlow, Timothy. "Integration of Grid Fins for the Optimal Design of Missile Systems." PhD diss., 2014. 
[18] Sh. Sham Dol; S. Shahid Pervaiz; M. Uzair; Sh. Khalid Bashir; M. Mustafa Elzughbi. "Design of Solar-powered Endurance Glider with Vortex Generators". Journal of Renewable Energy Research and Application (RERA), 2020.

[19] Sharul Sham Dol, Siaw Khur Wee, Hiang Bin Chan, Perumal Kumar, "Turbulence Characteristics behind a Flexible Vortex Generator", WSEAS TRANSACTIONS ON FLUID MECHANICS, 14, pp. 1-7, 2019.

[20] Alekseev, A., A. Maksimov, and A. Tarasov. "CFD investigations of the effect of rotating wheels, ride height and wheelhouse geometry on the drag coefficient of electric vehicle." International Journal of Mechanics 14 (2020): 130-134.

[21] Yong, T. H., and Sharul Sham Dol. "Design and development of low-cost wind tunnel for educational purpose." In IOP Conference Series: Materials Science and Engineering, vol. 78, no. 1, p. 012039. IOP Publishing, 2015.

[22] Dol, Sharul Sham, and MA Mohd Nor. "Flow visualization of the vortex shedding of a stationary circular cylinder by an improved smoke-wire technique." WSEAS transactions on fluid mechanics 1, no. 6 (2006): 745.

[23] Dol, Sharul S. "Weakened vortex shedding from a rotating cylinder." International Journal of Mechanical and Mechatronics Engineering 7, no. 10 (2013).

\section{Creative Commons Attribution License 4.0 (Attribution 4.0 International, CC BY 4.0)}

This article is published under the terms of the Creative Commons Attribution License 4.0

https://creativecommons.org/licenses/by/4.0/deed.en_US 